\title{
Post-Ebola Epidemic and Sustenance of Healthy Behaviour, Looking Back and Moving Forward
}

\author{
Veronica Akwenabuaye Undelikwo ${ }^{1, *}$, Rosemary Ine Eneji ${ }^{1}$ \& Eucharia Nwabugo Nwagbara ${ }^{1}$ \\ ${ }^{1}$ Department of Sociology, University of Calabar, Calabar, Cross River State, Nigeria \\ *Correspondence: Department of Sociology, University of Calabar, Calabar, Cross River \\ State, Nigeria. E-mail: vundelikwo@yahoo.com
}

Received: September 3, 2018 Accepted: November 2, 2018 Published: January 20, 2019

doi:10.5296/jsr.v10i1.13595 URL: https://doi.org/10.5296/jsr.v10i1.13595

\begin{abstract}
In 2014 the Ebola virus disease became a significant health challenge in much of West Africa, notably Guinea, Liberia, Sierra Leone, even Nigeria. The Ebola epidemic knows no geographical boundary as both developed and developing countries are susceptible to its menace. Key facts about the disease and what could be done to mitigate its spread were awash in both the print and electronic media at the height of its outbreak. There was increased awareness of personal hygiene practices of constant washing of hands and using hand-sanitizers. Body temperature was checked in public places such as airports, schools, etc. There were hardly anywhere, home or organization that you will not find sanitizers and clean water dispensers for hand-washing strategically stationed. 798 respondents from the University of Calabar (staff and students) were surveyed as well as five key informants for in-depth information on what has become of the healthy hygienic practices, and to determine whether Nigerians are still conscious of Ebola and how to achieve sustained healthy practices even after the epidemic. These preventive practices need to be intensified and sustained to consolidate the gains attained in the fight against the dreaded virus. We found a total decline in safety practices by individuals and organizations and this itself raises a major concern about their repercussions, given the paucity and unpreparedness of healthcare facilities. Worse still, relevant agencies such as the print and electronic media are no longer carrying out the awareness campaign.
\end{abstract}

Keywords: Ebola, epidemic, sustenance, healthy practices, behaviour 


\section{Introduction}

The outbreak of epidemic and other infectious diseases elicit frenzy responses and reactions at the structural, systemic, community and individual levels. The most vigorous, critical and impactful interventions at the individual level are geared towards behaviour change and adoption of acceptable healthy practices. This was clearly demonstrated in the advent of the Ebola virus disease outbreak. The Ebola virus disease (EVD) emerged as an epidemic with a tremendous threat to both developing and developed countries with no regards to geographical boundaries, exposing the inadequacies in our epidemic emergency response and preparedness.

The name Ebola originated from the Ebola River where the virus first appeared (Fasina, 2015). Ebola Virus Disease (EVD), also called hemorrhagic fever, is caused by a virus traditionally hosted by wild animals like Chimpanzees and gorillas and later transmitted to humans through direct contact with the animals, especially the animal fluid like blood, sweat, etc. According to Anaya and Duran cited in Weizman (2015), the Ebola virus was first discovered in 1976 in the Democratic Republic of Congo with other reported isolated outbreaks but generally in the rural areas of Central Africa. These outbreaks had all been effectively controlled until the 2014 outbreak, which for the first time affected the dense urban populations of Guinea, Sierra Leone and Liberia, making it the largest outbreak to date. Grady (2014) reported EVD in Yambuku, Republic of Congo during the first phase of the outbreak. Lack of human and infrastructural resources has hastened the spread of the virus. According to the International Health Regulations (2005), EVD has four species: Zaire, Bundibugyo, Reston and Tai forest. This agency noted that the first three species are prevalent in African countries.

The incubation period for Ebola Virus is between 2 and 21 days with symptoms such as rashes, fever, fatigue, sore throat, headache, muscle pain, etc. These are often preceded by vomiting and diarrhea; liver and kidney functions may be impaired. The symptoms develop into EVD when the clinical examination shows low white blood cell and platelet count of enzymes. The disease causes an acute illness which later results to fatality (Achalo, 2013).

Health Care Workers are sometimes seriously infected with the virus while rendering medical services to the patients of Ebola, thereby serving as means of transmission (Adetola, 2014). During burial rites of Ebola virus victims, a close contact with the deceased can lead to its transmission (Nguku, 2014). It can also be transmitted through sexual intercourse, especially on the prevalence of viable and transmissible virus in semen.

In 2014, the disease became a significant health challenge in West Africa, notably Liberia, Guinea, Sierra Leone, and even Nigeria. The Ebola virus arrived Nigeria through Patrick Sawyer, a Liberian-American who flew into Lagos from Monrovia on the $20^{\text {th }} \mathrm{July}$, 2014. The medical doctor who treated him when he became critically ill on arrival and few other health personnel that had contact with him also died of the virus. With the Ebola outbreak declaration in Nigeria, an Ebola Emergency Operation Centre (EEOC) to curb the spread of the virus was established through collaboration by the Federal Ministry of Health (FMOH/NCDC), the Nigerian Center for Disease Control, the Lagos State Ministry of Health and other partners (Gidado et al., 2015). Some of the measures for curbing the spread 
included quick allocation and disbursement of funds, building of isolated treatment facilities in Lagos and Port Harcourt, rigorous contact tracing, house to house information campaigns and messages on local radio stations (WHO, 2015). Being highly lethal with no vaccine or cure, the principal source of protection during Ebola outbreak is information aimed at behaviour change.

The reaction to the existence of the Ebola virus disease created a significant behaviour modification, high level of consciousness and the adoption of healthy living and sanitation practices in Nigeria. The print, electronic and social media disseminated information and messages geared towards creating awareness, educating and protecting people from new infections. During the Ebola outbreak, the people were receptive to health education and adopted a number of precautionary measures such as avoiding indiscriminate personal contacts, being mindful of the pets they keep and the type of meat to eat. Hand washing became a ritual; schools and other public institutions provided soap and water for their students, staff and visitors. "Taking body temperatures with infra-red thermometer was also in vogue" (Haastrup, 2016: 71). According to Gidado et al. (2015: 1), "the social mobilization and communication team of the EEOC conducted targeted house-to- house EVD education activities in the areas where cases and contacts of people with EVD lived. Widespread campaigns were implemented in the state on mass and social media platforms providing health promotion messages that aimed to address public concerns and promote adoption of EVD preventive/risk reduction behaviour to reduce community transmission."

Kama-Kleghe (2015) averred that, Hand sanitizers and other personal protective equipment (PPE) kits in Nigeria were in high demand and also in sufficient supplies across health care facilities, banks, schools, restaurants and hotel due to the believe that it could help prevent its spread across staff, students and visitors. This behaviour was occasioned by the fear from the threat of a dangerous infection. During the active phase of the pandemic, hand hygiene management was meticulously practice but this was short lived with the WHO declaration of Nigeria as Ebola free. The impression was that Nigeria is "safe to go back to business as usual". The country would have catch on the opportunity to strengthen infection prevention and control that was relatively weak. There was an obvious indifference and near apathy to infection prevention and control. This is especially true of hand hygiene, the very fundamental of infection prevention measures in general population.

"The fear of the Ebola virus disease during the last outbreak in Nigeria affected and threatened the social fabric of the country" (Ilesanmi \& Alele, 2016: 9). The behaviours adopted by Nigerians during the pandemic have not been sustained with the declaration of Nigeria as free of Ebola virus disease. However, "the EVD is neither the first nor the last public health emergency to threaten the ability of countries to provide basic services and longer term support to strengthen countries coping mechanisms that will help them prepare for unforeseen eventualities." (UNESCO, 2014: 8).

Weizman (2015) stated that the EVD served as a warning on health hygiene, sanitary and educational circumstances in the countries that were most affected. Hopefully, recovery from the outbreak will be a motive for these countries to improve and implement previous 
commitments to medical care and infrastructure, despite the setbacks. There is a very discernable and apparent decline in safety practices by individuals and organizations and this is dangerous because of the paucity and unpreparedness of our healthcare system.

The rigorous health education and awareness campaign by relevant agencies such as the mass media and outreaches are no longer prioritized. Thus, there is need for some retrospective consideration to achieve enduring and responsive healthcare delivery, but questions still remain: Why are healthy hygienic practices not sustained and consistent? Are Nigerians still conscious of Ebola virus disease and the fact that we are still susceptible to new infections? How can the health seeking-behaviour and attitudes of the people in the period of epidemic outbreak be strengthened and retained? What is the interplay of knowledge, benefits and fear evidence in the response to Ebola that drives and sustain healthy practices and behaviour? Here, we critically examine and address these questions as a valuable contribution to achieving improved healthy practices and health outcome.

\section{Theoretical Framework}

\subsection{The Health Belief Model}

This study is anchored on the health belief model. In the 1950s, Social Psychologists Godfrey M. Hochbaum, Irwin Rosenstock and Stephen Kegels developed the health belief model to explain how individual beliefs on health conditions can predict their health related behaviours. The model proposed the following five factors that explain why an individual will or will not adopt some health behaviours, depending on the perceived threats and benefits:

1. Perceived susceptibility

2. Perceived severity

3. Perceived benefits of taking action

4. Perceived barriers to taking action

5. Cues to action

In 1988 Rosenstock and others added the concept of self-efficacy or the confidence in the ability of the individual to perform an action to the health belief model to better fit the challenges of changing habitual unhealthy behaviours (Onoruoiza et al., 2015).

Perceived Susceptibility: Every individual has a personal perception of the risk of developing a health problem and the perceived susceptibility to developing a particular health condition will determine the behaviour engaged in by the individual to reduce the risk of developing the health problem. Those who perceived a low susceptibility are more likely to engage in unhealthy or risky behaviours while those who perceive a high susceptibility are more likely to engage in behaviours to decrease their chances of developing the condition.

People's actions are predicated on the belief that during the Ebola epidemic they were in danger and susceptible to the infection and hence adopted hygienic practices; those who perceived low susceptibility occasionally adopted hygienic practices and after the declaration of the country as Ebola free, compliance with hygienic practices both by individuals and 
government relapsed.

Perceived Severity: This is an assessment of the severity of a health problem and its potential consequences. An individual who perceive a given health problem as serious will more likely engage in behaviours to prevent it from occurring or reduce its severity.

The combination of perceived seriousness and perceived susceptibility is referred to as perceived threat. This model predicts that a high-perceived threat is likely to promote positive health behaviours.

Ebola virus disease was perceived as serious, life threatening and resulting in high death rate plus the isolation of those infected from their families and work places. This perceived severity made people to engage in hygienic behaviours to prevent contacting the virus.

Perceived Benefits Of Taking Action: The perceived benefits of taking action also influences health related behaviours. An individual's assessment of the benefit of engaging in a particular health promoting behaviour in order to reduce the risk of a disease is influenced by his or her beliefs regarding the benefits of the action. For instance, an individual who believes that engaging in a particular action will reduce his/her susceptibility to a health problem will engage in that behaviour.

Self-efficacy: This is the belief in an individual's own ability to do something. People who did not adopt hygienic practices during the Ebola epidemic had low self-efficacy and those who did had high self-efficacy.

Nigerians engaged in adopting hygienic practices in order to avoid the risk of getting infected with Ebola virus. Most persons washed their hands regularly with soap and water, moved around with hand sanitizers and avoided shaking hands with or hugging people, contact with blood and body fluids of people and funeral and burial rituals that required handling the human body, etc. On the part of Government and other Institutions, hand sanitizers, soap and water were placed at all public places. Body temperatures were also checked. Nigerians did this due to the belief that it will reduce their susceptibility. Those who did not believe were less likely to adopt the hygienic practices.

Perceived Barriers To Taking Action: Health related behaviours are also a function of perceived barriers to taking action. The obstacle to an individual in adopting a behaviour change is the perceived barrier. The perceived barriers may prevent an individual from engaging in positive health behaviour even when the health condition is perceived as threatening and there is perceived benefits of taking action. For behaviour change to occur the perceived benefits must outweigh the perceived barriers. Perceived barriers include for example perceived inconvenience, side effects of a medical procedure, discomfort etc. During the Ebola epidemic a large number of persons adopted hygienic practice due to limited perceived barrier to taking action.

Cues To Action: For health promoting behaviour to be adopted, a cue or trigger is necessary. This could be internal or external. Physiological cues such as pain, symptoms are example of internal cues to action while information from close persons, the media, and health care 
providers are external cues to action. The intensity of cues to prompt action varies from one individual to another by the perceived susceptibility, severity, benefits and barriers. For example, during the Ebola epidemic, people who believed they were at risk were easily persuaded to adopt hygienic practices due to the numerous awareness and sensitization and advice from medical practitioners. Also the various symptoms of the Ebola disease prompted people to take action to prevent contacting the virus.

\section{Objectives of the Study}

The study seeks to:

1. Establish what influences the behaviour of individuals toward the adoption of hygienic practices during an epidemic outbreak.

2. Determine why healthy hygienic practices are not sustained after the Ebola outbreak.

3. Determine the factors necessary for sustainable healthy behaviour and practices during and after an epidemic.

\section{Research Questions}

1. What are the possible factors influencing the behaviour of individuals toward the adoption of hygienic practices during an epidemic outbreak.

2. What are the possible factors influencing non-sustenance of hygienic behaviour of individuals after Ebola epidemic outbreak.

\section{Hypotheses}

1. There is no significant difference between practices adopted during and after Ebola epidemic among residents in University of Calabar community.

2. The behaviour of respondents will be significantly different when there is another outbreak of Ebola.

\section{Methodology}

Seven hundred and ninety-eight (798) respondents from the University of Calabar (staff and full time students) were studied using accidental sampling techniques, in addition to five key informants for in-depth information on pertinent post-Ebola issues, some of which included: relaxed or near absence of consciousness about safety behaviour; preparedness and availability of equipment; designated centres to forestall future occurrence; and, frozen mass media awareness campaign, jingles, among others. The goal was to gather primary data that reveal knowledge about post-Ebola behaviours and attitudes as well as provide information that will assist in planning or designing of development policies and programmes. The study 
was performed using standard questionnaires consisting of two parts, namely: the demographic information section and the substantive section. The demographic information section covered personal information from the respondents' while the substantive section was devoted to information on the key variables under study. The key informants included the Chief Medical Director of the University of Calabar Medical Centre, a medical doctor, a nurse, a laboratory technician and a pharmacist, all from the same facility. Pearson Chi-square was used to analyse the data generated from the field as well as simple percentage. Accidental sampling was used to select respondents (staff- academic/non-academic and full-time students) for the study. Samples were selected from the twelve faculties of the University (Agriculture, Allied Medical Sciences, Art, Basic Medical Sciences, Biological Sciences, College of Medicine and Dentistry, Law, Physical Sciences, Education, Social Sciences, Management Sciences and Institute of Oceanography).

\section{Presentation of Socio-Demographic Data of Respondents}

Table 1. Demographic data: Sex

\begin{tabular}{lccc}
\hline Variable & Category & N & Percent $(\%)$ \\
\hline Sex & Male & 443 & 55.5 \\
& Female & 355 & 44.5 \\
& Total & 798 & 100 \\
\hline
\end{tabular}

Source: Field survey 2017

Table 1 revealed respondents' demographic information. The responses to the questionnaire in respect to sex reveal that, most of the respondents $443(55.5 \%)$ were male while 355 $(44.5 \%)$ were female. This result shows that, there are more male respondents in our sample and this is similar to the population.

Table 2. Demographic Data: Age

\begin{tabular}{llll}
\hline Variable & \multicolumn{1}{c}{ Category } & $\mathrm{N}$ & Percent $(\%)$ \\
\hline Age & 20 years and below & 156 & 19.5 \\
& 21-30 years & 295 & 37.0 \\
& 31-40 years & 144 & 18.0 \\
& 41 years and above & 203 & 25.4 \\
& Total & 798 & 100 \\
\hline
\end{tabular}

Source: Field survey, 2017

Table 2 shows that, out of the respondents used in this study, 156 representing $19.5 \%$ were 20 years and below; 295 (37.0\%) were between 21 -30 years; 144 respondents representing $18.0 \%$ were 31 - 40 years while 203 respondents representing $25.4 \%$ were 41 years and above in age. This trend is a true representation of the population, since must respondents are students (undergraduate and post graduate). 


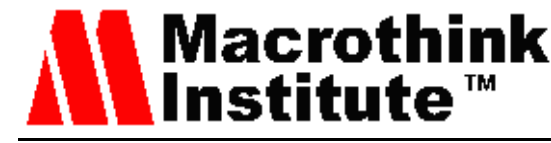

Table 3. Demographic Data: Designation

\begin{tabular}{llll}
\hline Variable & Category & N & Percent $(\%)$ \\
\hline Designation & Student & 432 & 54.1 \\
& Non-academic staff & 299 & 37.5 \\
& Academic staff & 67 & 8.4 \\
& Total & 798 & 100 \\
\hline
\end{tabular}

Source: Field survey, 2017

The distribution of respondents' base on designation in table 3 shows that, most of the respondents' 432 (54.1\%) were students (undergraduate and post-graduate); 299 respondents representing $37.5 \%$ were non-academic staff while only 67 respondents representing $8.4 \%$ were academic staff.

\section{Results and Discussion}

8.1 Data Testing the Null Hypothesis That There is no Significant Difference between Practices Adopted during and after Ebola Epidemic among Residents in University of Calabar Community Are Shown in Table 4.

The hygienic practices of respondents during Ebola epidemic outbreak differed from those adopted after the outbreak. Out of the 798 respondents, 597 (74.8\%) washed their hands with soap and water regularly during Ebola epidemic outbreak but the number reduced to only 384 (48.1\%) after the Ebola epidemic. Whereas $45.6 \%$ of the 798 respondents always moved around with hand sanitizers during the epidemic outbreak, a mere $13.0 \%$ did so after the epidemic. Also, $34.0 \%$ of the respondents avoided shaking hands with people during the outbreak while the number reduced to only $8.5 \%$ after the epidemic. Similarly, $212(26.6 \%)$ respondents avoided hugging people during the outbreak while the number reduced to only $54(6.8 \%)$ after the epidemic.

About $29.2 \%$ of the respondents avoided any physical bodily contact with people during the outbreak while only $10.7 \%$ did so after the epidemic. Response also showed that $49.0 \%$ of the respondents avoided contact with blood and body fluids of people during Ebola epidemic outbreak while $32.0 \%$ did so after the epidemic. Also, $25.1 \%$ of the respondents avoided funeral and burial rituals that required handling the body of people during the Ebola epidemic while the ratio reduced to $12.5 \%$ after the epidemic. This finding is in agreement with Goorah, Dewkurun and Ramchurn (2013) who in a study on Assessing the sustainability of individual change against mosquitoes after an outbreak of a vector-borne disease in Mauritius found a substantial difference in practices adopted during and after the outbreak. They found a significant increase in participants adopting at least six measures to drain stagnant water and tackle mosquito-breeding sites compared to the post-outbreak period where people were practicing between 2 to 5 interventions. 


\section{Mll Macrothink}

Table 4. Pearson Chi-square Analysis of Practices Adopted during Ebola and after Ebola Outbreak

\begin{tabular}{|c|c|c|c|c|c|}
\hline Practices & $\begin{array}{l}\text { No. Who } \\
\text { Adopted } \\
\text { During Ebola }\end{array}$ & $\begin{array}{l}\text { No. Who } \\
\text { did not } \\
\text { adopt }\end{array}$ & $\begin{array}{l}\text { No. Who } \\
\text { Adopted } \\
\text { after }\end{array}$ & $\begin{array}{l}\text { No. Who } \\
\text { do not } \\
\text { adopt }\end{array}$ & Chi-square \\
\hline Washing my hands with & 597 & 201 & 384 & 414 & $44.17 *$ \\
\hline Soap and water regularly & $(74.8)$ & $(25.2)$ & $(48.1)$ & $(51.9)$ & \\
\hline Always moving around & 364 & 434 & 104 & 694 & $44.39 *$ \\
\hline With hand sanitizers & $(45.6)$ & $(54.4)$ & $(13.0)$ & $(87.0)$ & \\
\hline Avoid shaking hands & 271 & 527 & 68 & 730 & $48.11^{*}$ \\
\hline With people & $(34.0)$ & $(66.0)$ & $(8.5)$ & $(91.5)$ & \\
\hline \multirow[t]{2}{*}{ Avoid hugging people } & 212 & 586 & 54 & 744 & $43.43^{*}$ \\
\hline & $(26.6)$ & $(70.8)$ & $(6.8)$ & $(93.2)$ & \\
\hline Avoid physical bodily & 233 & 565 & 85 & 713 & $54.24 *$ \\
\hline Contact with people & $(29.2)$ & $(70.8)$ & $(10.7)$ & $(89.3)$ & \\
\hline Avoid contact with blood & 391 & 407 & 255 & 543 & $187.03 *$ \\
\hline And body fluids of people & $(49.0)$ & $(51.0)$ & $(32.0)$ & $(68.0)$ & \\
\hline Avoid funeral and burial & 200 & 598 & 100 & 698 & $170.58 *$ \\
\hline Rituals that required & $(25.1)$ & $(74.9)$ & $(12.5)$ & $(87.5)$ & \\
\hline $\begin{array}{l}\text { Handling the body of } \\
\text { people }\end{array}$ & & & & & \\
\hline
\end{tabular}

Source: Field survey, 2017

*Percentages are written in parenthesis

$*$ Significant at 0.05 level; $\mathrm{df}=1$; critical chi-square $=3.841$

On how to sustain the hygienic practices adopted during the Ebola epidemic, a key informant said that:

"Enlightenment campaigns, sustaining continuous enlightenment, the amount of enlightenment that was on then is not available now, it too has to be sustained for a long time, so that it becomes part of everybody, you know children and adults can recite. If you ask some people questions on these steps now, they may have forgotten. It has to be a continuous education of the populace about the steps they can take to prevent them. Water is a government thing, water is an issue, there are some areas that even when you want to wash there is no water, you know that's up to the government to provide".

Another respondent equally suggested that continuous sensitization is a sure way of sustaining the practices Nigerians adopted during the Ebola epidemic:

"We can sustain the practices with or without Ebola if the sensitization is there, because if we continue to sensitize people, they will become conscious of how they go about their hygiene. So, the major thing is the sensitization. In our own little 
community here, while patients are waiting for a doctor, they should be sensitized about hygienic practices, I think that will go a long way to help".

8.2 Analysis of Data Testing the Hypothesis That the Behaviour of Respondents Will Be Significantly Different When There is Another Outbreak of Ebola is shown in Table 5

Table 5. Chi-square Analysis of Behaviour at Present and When There is Another Outbreak of Ebola

\begin{tabular}{|c|c|c|c|c|c|}
\hline & \multicolumn{2}{|l|}{ At present } & \multicolumn{2}{|l|}{ Chi-square } & \\
\hline & No. $(\%)$ & No. $(\%)$ & No. $(\%)$ who & No. $(\%)$ who & \\
\hline & $\begin{array}{l}\text { adopting } \\
\text { hygienic } \\
\text { behaviour } \\
\text { behaviour }\end{array}$ & $\begin{array}{l}\text { Not } \\
\text { adopting } \\
\text { hygienic }\end{array}$ & $\begin{array}{l}\text { will adopt } \\
\text { hygienic } \\
\text { behaviour } \\
\text { behaviour }\end{array}$ & $\begin{array}{l}\text { will not } \\
\text { adopt } \\
\text { hygienic }\end{array}$ & \\
\hline $\begin{array}{l}\text { Always have hand } \\
\text { sanitizer with me }\end{array}$ & $364(45.6)$ & $434(54.6)$ & 709 (88.8) & $89(11.2)$ & $53.78^{*}$ \\
\hline $\begin{array}{l}\text { Regular hand } \\
\text { washing }\end{array}$ & $487(61.0)$ & $311(39.0)$ & $652(81.7)$ & $146(18.3)$ & $49.21^{*}$ \\
\hline $\begin{array}{l}\text { Avoid physical } \\
\text { Contact }\end{array}$ & $212(26.6)$ & $586(73.4)$ & 734 (92.0) & $64(8.0)$ & $60.98^{*}$ \\
\hline $\begin{array}{l}\text { Sustain hygienic } \\
\text { practices adopted } \\
\text { during Ebola } \\
\text { outbreak }\end{array}$ & $271(34.0)$ & $527(66.0)$ & $633(79.3)$ & 165 (20.7) & $62.54 *$ \\
\hline
\end{tabular}

Source: Field survey, 2017

As shown in Table 5, there were significant differences in the frequency of respondents who are adopting hygienic behaviour currently when there is no outbreak of Ebola and when there is another outbreak in the future. Out of the 798 respondents, $45.6 \%$ always had hand sanitizers but $88.8 \%$ will be willing to have them during future outbreaks; $61.0 \%$ practiced hand washing while $81.7 \%$ will do so in future outbreaks, $26.6 \%$ were avoiding physical contact but $92 \%$ were willing to do so during future outbreaks; $34.0 \%$ of the respondents were sustaining hygienic practices but $79.3 \%$ of them were willing to sustain hygienic practices during future outbreaks. This finding is in disagreement with Haastrup (2016) who found that Lagos residents' preventive health behaviour during the post-Ebola epidemic and likely preventive health behaviour in future occurrence is not significantly different.

8.3 Factors Influencing the Behaviour of Individuals toward the Adoption of Hygienic Practices during an Epidemic Outbreak. 
Table 6. Factors Influencing the Behaviour of Individuals during an Epidemic Outbreak

\begin{tabular}{lcc}
\hline Factors & $\mathrm{N}(\%)$ & Ranked \\
\hline Fear of contacting Ebola & $561(70.3)$ & $1^{\text {st }}$ \\
Prevention measures & $159(19.9)$ & $2^{\text {nd }}$ \\
Enlightenment campaign & $29(3.6)$ & $3^{\text {rd }}$ \\
To end the spread of Ebola & $25(3.1)$ & $4^{\text {th }}$ \\
Medical precautions & $24(3.0)$ & $5^{\text {th }}$ \\
\hline
\end{tabular}

Source: Field survey, 2017

As shown in Table 6, there are five known reasons why residents in the study area adopted hygienic practices during the outbreak of Ebola, the most potent being the fear of contacting Ebola; seventy per cent of the respondents alluded to the fact. About $20 \%$ of the respondents reported preventive measures, $3.6 \%$ considered enlightenment campaign, while a small percentage 3.1 and 3.0 considered the attempts to end the spread of Ebola and medical precautions as factors influencing behaviour during an epidemic. The finding is supported by Nyakarahuka et al. (2017) who in a study in Uganda reported that there was much fear among the respondents who believed that Ebola and Marburg viral diseases could kill instantly, causing chaos and are more severe than HIV. Ebola was considered a terrible disease eliciting fear at the mention of its name. They equally reported that the community proposed recurring sensitization to create awareness.

The following statements from some key informants amply illuminate this finding:

"I think that anytime you have an epidemic which is very scary like the one we are talking about people will change their behaviour. The fear of Ebola became the beginning of wisdom in almost every sphere of life. The people were seeing pictures, clips from other countries where it was very serious, even the way people were dressing, the way the health workers were dressing to attend to them and the number of casualties was increasing, morbidity and mortality. Even the way they dress to go and dispose the corpse. And then here in Nigeria, the man who visited Nigeria, the doctors and nurses who attended to him were infected. The quarantine and the contact tracing. It became very obvious that anything you said at that time would be taken immediately, very much unlike introducing anything new. It takes a long time for people to imbibe new thing. If you say wash your hands, maintain hygiene, it becomes very difficult for people to imbibe it. But, because of the fear, they saw that if you do not do, you would be in trouble. Very few did not observe, they complied. Compliance was almost $100 \%$. You can see now, after the Ebola, when the situation on ground became like normalcy has been restored, how many people are still washing their hands? How many are still maintaining hygiene? So, people respond because of what is before them, the kind of things they see, the dangers ahead".

"I think it is because of the sensitization that might have influenced them. Secondly, which is the most important aspect is the fear of the Ebola knowing fully well that it 
kills very fast and for the fact that there was no cure to it".

"Ultimately, the fear of getting the infection, bearing in mind that most cases that were identified led to death of the patients. There was no definitive treatment. So, every body was scared of dying, no body wanted to get the infection. Adopting hygienic practices appeared to be the simple way of preventing the infection, so of course every body had to adopt it".

\subsection{Possible Reasons for Non-Sustenance of Hygienic Behaviour after Ebola Epidemic} Outbreak

Table 7. Reasons for Non-Sustenance of Hygienic Behaviour of Individuals

\begin{tabular}{lcc}
\hline Factors & $\mathrm{N}(\%)$ & Ranked \\
\hline Poverty & $694(87)$ & $1^{\text {st }}$ \\
Lack of sensitization & $51(6.4)$ & $2^{\text {nd }}$ \\
Lack of legislation & $31(3.9)$ & $3^{\text {rd }}$ \\
No motivation & $10(1.3)$ & $4^{\text {th }}$ \\
Not necessary & $12(1.5)$ & $5^{\text {th }}$ \\
\hline
\end{tabular}

Source: Field survey, 2017

There were five known reasons for the non-sustenance of hygienic behaviour by residents in the study area after the outbreak of Ebola (Table 7); the most potent factor according to 87\% of the respondents was poverty. Lack of sensitization was identified as a reason by $6.4 \%$, lack of legislation by $3.9 \%$, lack of motivation by $1.3 \%$ while $1.5 \%$ of the respondents considered that it was not necessary to sustain hygienic practices since there was no more Ebola.

In the words of some respondents from the key informant interviews:

"I think clearly, we Nigerians pay more attention to what government brings to us, the laws that are made for us. We do not relate them to who the chief beneficiary is. We wait on what government say we should do".

"The simple fact is that there is no continuous sensitization".

"The money is not there to continue to put those things in place".

"Ignorance is there. You do not need to be scared of picking up an infection for you to see the need to maintain hygiene. Also, the economic issues, you will be surprised to know that some people may find it difficult to get soap, hand sanitizers".

\section{Conclusion/ Recommendations}

Findings from this study indicate that Nigerians wait until there is an epidemic outbreak before adopting precautionary measures. Both the government and the people are not proactive but they are rather reactive. There is need for adoption of hygienic practices as a 
way of life to forestall huge casualties in event of an epidemic outbreak. The frenzy sensitization and awareness campaigns embarked upon by the government and people should be a continuous thing, given the fact that we have a slow response rate to emergencies coupled with the lack of basic facilities at our hospitals. All stakeholders must play their part in inculcating basic hygienic practices in the people. The provision of soap and water as well as hand sanitizers at public places should be sustained. The decline in safety practices by individuals and organizations should be addressed due to its repercussions given the paucity and unpreparedness of health care facilities. These preventive practices need to be intensified and sustained to consolidate the gains attained in the fight against the dreaded virus.

\section{References}

Achalo, E. O (2013). Disease Control. Port Harcourt: Uniport Press.

Adetola, O. N (2014). Medical dialysis of virus. Ibadan: PEX PRESS.

Fasina, F. O. (2015). Transmission dynamics and control of Ebola Virus in Nigeria. Sweden: Rapid communication.

Gidado, S., Oladimeji, A. M., Roberts, A. A., Nguku, P., Nwangwu, I. G., Waziri, N. E., Shuaib, F., Oguntimehin. O., Musa, E., Nzuki, C., Nasidi, A., Adewuyi, P., Daniel, T., Olayinka, A., Odubanjo, O., \& Poggensee, G. (September, 2015). Public Knowledge, Perception and Source of Information on Ebola Virus Disease- Lagos, Nigeria. PLOS $\begin{array}{llllll}\text { Currents } & \text { Outbreaks. } & 2015 & \text { Apr } & 8 . & \text { Edition }\end{array}$ https://doi.org/10.1371/currents.outbreaks.0b805cac244d700a47d6a3713ef2d6db

Goorah, S., Dewkurun, M. K., \& Ramchurn, S. K. (2013). Assessing the sustainability of individual behaviour change against mosquitoes after an outbreak of a vector- borne disease in Mauritius: a case study. Internet Journal of Medical Update, 8(1), 9-16.

Grady, D. F. (2014). Tracing the Ebola outbreak. New York: NEJ publishers.

Haastrup, A. (2016). Preventive Health Practices in an Ebola Virus Disease Free Period. International J. Soc. Sci. and Education, 2(1), 71-80.

Ilesanmi, O., \& Alele, F. O. (4 ${ }^{\text {th }}$ March, 2016). Knowledge, Attitude and Perception of Ebola Virus Disease among Secondary School Students in Ondo State, Nigeria, October, 2014. PLOS Currents Outbreaks. 2016 Mar 4. Edition 1. https://doi.org/10.1371/currents.outbreaks.c04b88cd5cd03cccb99e125657eecd76

Kama-Kleghe, S. (2015). Nigeria: Hand Hygiene after Pandemics. Fanny, J. (Ed). Retrieved December 14, $2015 \quad$ from http://infectioncontrol.tips/2015/12/14/hand-hygiene-after-pandemics-dealing-with-beha viour-in-nigerian-practice/

Nguku, P. O. (2014). Training and Services in Public health. Journal of Epidemiology, 2(1), 8-12. 


\section{Macrothink}

Nyakarahuka, L., Skjerve, E., Nabadda, D., Sitali, D. C., Mumba, C., Mwiine, F. N., Lutwama, J. J., Balinandi, S., Shoemaker, T., \& Kankya, C. (2017). Knowledge and Attitude towards Ebola and Marburg Virus diseases in Uganda using quantitative and participatory epidemiology techniques. PLoS NegL Trop Dis., 11(9), e0005907. https://doi.org/10.1371/journal.pntd.0005907

Onoruoiza, S. I., Musa, A., Umar, B. D., \& Kunle, Y. S. (2015). Using Health Beliefs Model as an Intervention to Non Compliance with Hypertension Information among Hypertensive Patient. IOSR Journal Of Humanities And Social Science, 20(9), 11-16.

UNESCO (2014). UNESCO's Response to Ebola. Strategy Paper. Retrieved December, 2014 from http://unesdoc.unesco.org/images/0023/002311/231158e.pdf

Weizman, M. J. (2015). Analysis of the 2014 Ebola Outbreak in Guinea, Sierra Leone and Liberia. Retrieved August 14, 2015 from https://reliefweb.int/report/sierra-leone/analysis-2014-ebola-outbreak-guinea-sierra-leon e-and-liberia

WHO (2015). Successful Ebola Responses in Nigeria, Senegal and Mali. One year into the $\begin{array}{lllll}\text { Ebola Epidemic. } & \text { Retrieved } & \text { January, } & 2015\end{array}$ http://www.who.int/csr/disease/ebola/one-year-report/nigeria/en/

\section{Copyright Disclaimer}

Copyright for this article is retained by the author(s), with first publication rights granted to the journal.

This is an open-access article distributed under the terms and conditions of the Creative Commons Attribution license (http://creativecommons.org/licenses/by/3.0/). 